\title{
Lack of neurologic improvement after aortic repair for acute type A aortic dissection complicated by cerebral malperfusion: Predictors and association with survival
}

\author{
Naoto Morimoto, MD, Kenji Okada, MD, and Yutaka Okita, MD
}

Background: Surgical treatment of acute type A aortic dissection complicated by cerebral malperfusion remains challenging. This study evaluated predictors of lack of neurologic improvement after aortic repair for acute type A dissection complicated by cerebral malperfusion and assessed relationship with survival.

\begin{abstract}
Methods: We retrospectively reviewed 41 consecutive patients operated on between 1999 and 2008 for acute type A dissection complicated by cerebral malperfusion. Lack of postoperative neurologic improvement was defined as a difference between baseline and postoperative National Institutes of Health Stroke Scale scores of 3 points or less.

Results: Lack of neurologic improvement was seen in 15 patients (37\%). Logistic regression analysis, baseline National Institutes of Health Stroke Scale score (odds ratio, 6.7; 95\% confidence interval, 1.4-32.4; $P=.02$ ), and time to surgery (odds ratio, $14.6 ; 95 \%$ confidence interval, $2.7-8.5 ; P=.002$ ) were significantly associated with lack of neurologic improvement. In receiver operating characteristic analysis, National Institutes of Health Stroke Scale score greater than 11 and time to surgery longer than 9.1 hours were best cutoffs for predicting lack of neurologic improvement. Thirty-day mortality was $14.6 \%$. All early deaths were caused by large hemispheric infarction. Postoperative computed tomography or magnetic resonance imaging revealed cerebral infarction in 21 patients $(51 \%)$. Five-year survival was significantly lower in patients without neurologic improvement (33\% $\pm 12 \%$ vs $84 \% \pm 7 \%, \log$-rank $P<.001)$.
\end{abstract}

Conclusions: Time to surgery and baseline National Institutes of Health Stroke Scale score were predictors of lack of improvement, which was associated with poor survival. (J Thorac Cardiovasc Surg 2011;142:1540-4)

Acute type A aortic dissection is considered to be a surgical emergency, mandating immediate surgical repair. Preoperative malperfusion is a significant risk factor influencing perioperative and long-term survival after surgery for acute type A dissection. ${ }^{1}$ Preoperative neurologic deficits resulting from cerebral malperfusion have been reported as a sign of poor prognosis. Recently several authors ${ }^{1,2}$ have reported favorable outcomes of immediate surgical repair for acute type A dissection complicated by cerebral malperfusion. Even in these series, however, several patients had postoperative neurologic deterioration and eventual cerebral death. The effects of cardiopulmonary bypass and reperfusion on the ischemic brain has not been elucidated. Several factors, including the time to treatment, collateral circulation, extent of ischemia, and stroke subtype, may influence the response to reperfusion. ${ }^{3}$ Information on neurologic improvement after reperfusion thus may be useful to

From the Division of Cardiovascular Surgery, Kobe University Graduate School of Medicine, Kobe, Japan.

Disclosures: Authors have nothing to disclose with regard to commercial support.

Received for publication Feb 12, 2011; revisions received March 31, 2011; accepted

for publication May 5, 2011; available ahead of print June 13, 2011.

Address for reprints: Naoto Morimoto, MD, Division of Cardiovascular Surgery,

Kobe University Graduate School of Medicine, 7-5-1, Kusunoki-cho, chuo-ku,

Kobe, Hyogo, 650-0017, Japan (E-mail: naotofrcs@gmail.com).

0022-5223/\$36.00

Copyright (c) 2011 by The American Association for Thoracic Surgery

doi:10.1016/j.jtcvs.2011.05.004 establish the ideal therapeutic approach. The aim of this study was to evaluate perioperative and long-term results of patients with cerebral malperfusion in a single-center, retrospective study.

\section{MATERIALS AND METHODS}

We reviewed our institutional database to identify patients who had undergone surgery for acute type A dissection between October 1999 and March 2008. A total of 157 consecutive patients underwent surgery on an emergency basis for acute type A aortic dissection during this period. Patients who had cerebral malperfusion $(n=41)$ were included in this study. Approval of the institutional review board was obtained, and individual consent was waived.

Decisions regarding aortic surgery were based on several factors, such as duration from the onset of symptoms to the arrival at our hospital, neurologic symptoms, hemodynamic stability, the presence of pericardial effusion or cardiac tamponade, and the risk of rupture. Immediate aortic repair was performed in 37 patients after the establishment of the diagnosis of acute type A aortic dissection. The diagnosis of dissection was delayed in 4 cases because they were treated initially as stroke. These patients were referred to our surgical service 3 to 5 days after the onset of dissection. Among these patients, immediate surgery was performed in 2 cases because of cardiac tamponade, and the surgery was postponed for 2 patients in comas until their neurologic status was improved.

\section{Surgical Management}

All patients underwent median sternotomy with total cardiopulmonary bypass. Cardiopulmonary bypass was instituted with right axillary or right femoral arterial perfusion and right atrial drainage. Femoral arterial 


\section{Abbreviation and Acronym \\ NIHSS $=$ National Institutes of Health Stroke Scale}

perfusion was preferred early in this series. Systemic cooling was carried out down to a tympanic temperature of $18^{\circ} \mathrm{C}$ to $20^{\circ} \mathrm{C}$, with maximal temperature gradient of $6^{\circ} \mathrm{C}$. Currently, our brain protection method has shifted from retrograde cerebral perfusion to selective cerebral perfusion (perfusion rate $12-15 \mathrm{~mL} /[\mathrm{kg} \cdot \mathrm{min}])$ during circulatory arrest at a rectal temperature of $23^{\circ} \mathrm{C}$ to $25^{\circ} \mathrm{C}$. After systemic perfusion was stopped, the priority was to reestablish the blood flow to the malperfused brain tissue as soon as possible. Since March 2008, a controlled earlier reperfusion system ${ }^{4}$ has been adapted to start selective cerebral perfusion in the emergency department.

The extent of aortic replacement was decided according to the tearoriented approach. Total arch replacement was reserved for patients with aortic arch entry tears involving the supra-aortic orifices, as well as for patients with an enlarged aortic arch or other indications. ${ }^{5}$

\section{Definition of Cerebral Malperfusion}

Cerebral malperfusion was defined according to newly developed motor or sensory deficits from the carotid arterial system and required clinical evidence of lack of or decrease in carotid arterial blood flow on carotid ultrasonography or contrast-enhanced computed tomography. Patients with global cerebral ischemia as a result of shock or with spinal cord deficits from spinal cord ischemia were excluded. Evidence of a dissection membrane in aortic branch vessels without corresponding clinical signs or symptoms was not classified as malperfusion. The occlusion of the carotid artery was defined as undetectable Doppler flow signals on carotid ultrasonography.

\section{Classification of Stroke Severity}

Preoperative neurologic assessment was conducted with the National Institutes of Health Stroke Scale (NIHSS). ${ }^{6}$ The NIHSS is a validated 15 -item scale that is used to assess key components of the standard neurologic examination in patients with stroke. This scale assesses level of consciousness, ocular motility, facial and limb strength, sensory function, coordination, language, speech, and attention. Scores range from 0 (normal) to 40 (maximum deficit). Scores between 0 and 5 are generally classified as mild, whereas scores exceeding 15 are generally classified as severe.

\section{Outcome Measures}

Previous major stroke trials ${ }^{7-9}$ used a difference of 4 points or more on the NIHSS to reflect a clinically significant improvement. We defined lack of improvement as not more than a 3-point difference between the baseline and postoperative NIHSS scores.

\section{Follow-up}

Follow-up was achieved for $100 \%$ of hospital survivors. Follow-up consisted of a telephone interview with the patients or their family members, as well as a written questionnaire sent to the patients' general practitioners.

\section{Statistical Analysis}

Two exploratory analyses were performed. First, predictors of lack of neurologic improvement were identified. Continuous variables were expressed as median and range. Categoric variables were expressed as percentages. To make univariate comparisons between groups, the 2-tailed Student $t$ test was used for continuous variables and the $\chi^{2}$ test was used for categoric variables. The associations between demographic characteristics, clinical, variables, and hemodynamic variables and lack of improvement were examined with logistic regression. Continuous variables were dichotomized at the median and analyzed as categoric variables. We also retrospectively analyzed the number of patients at risk and the cumulative proportion of patients with lack of improvement by the time to surgery. Receiver operating characteristic curve analysis was used to determine optimal cutoff values for the time to surgery and the baseline NIHSS score in predicting lack of improvement.

Second, lack of neurologic improvement was evaluated as an association with poor long-term survival. Survival analysis was performed according to the Kaplan-Meier method, and statistical differences were analyzed with the log-rank test. Statistical analyses were performed with the SPSS version 11.0 software package (SPSS, Inc, an IBM Company, Chicago, Ill).

\section{RESULTS \\ Patient Characteristics}

From October 1999 to March 2008, a total of 157 patients with acute type A aortic dissection underwent aortic repair in our institution. During that period, 41 patients had cerebral malperfusion syndrome diagnosed. Of these 41 patients, 26 patients (group I) had neurologic improvement and 15 patients (group II) had lack of neurologic improvement after surgery (Table 1). With the exception of the time to surgery and the baseline NIHSS score, demographic and preoperative variables were similar between groups I and II.

The mean time from symptom onset to surgery was $21.7 \pm 40.5$ hours (median 6.5 hours). In the overall patient population, only $2.4 \%$ of patients were operated on within 3 hours of stroke onset. The mean baseline NIHSS score was $10.7 \pm 7.9$ (median 8.0). Neurologic deficits consisted of coma with seizure $(n=1)$, coma without seizure $(n=6)$, stupor $(\mathrm{n}=13)$, hemiplegia $(\mathrm{n}=9)$, hemiparesis $(\mathrm{n}=10)$, and hemianopsia $(\mathrm{n}=2)$. Preoperative computed tomography or magnetic resonance imaging of the brain was performed at $4.5 \pm 3.8$ hours from the onset of symptoms in 27 patients $(66 \%)$. No patient had apparent findings of stroke on computed tomography. Diffusion-weighted magnetic resonance imaging revealed early ischemic changes in 2 patients. Intraoperative management data of both groups are displayed in Table 1 . There were no major difference between groups with regard to cardiopulmonary bypass management or extent of aortic repair.

Comparisons of postoperative outcomes between groups are presented in Table 2. The mean postoperative NIHSS score was significantly lower in group I $(7.0 \pm 5.6$ vs 22.7 $\pm 14.7, P<.001)$. Postoperative computed tomography or magnetic resonance imaging revealed brain infarction in 23 patients. Among the 15 patients who had occlusion of the carotid artery before surgery, persistent occlusion after aortic repair was present in 3 patients. These 3 patients had large hemispheric infarction with brain edema.

\section{Predictors of Lack of Neurologic Improvement}

The baseline NIHSS score and the time to surgery were predictors of lack of neurologic improvement in the 
TABLE 1. Comparison of clinical characteristics and univariate analysis between groups I and II

\begin{tabular}{|c|c|c|c|}
\hline & $\begin{array}{l}\text { Group I } \\
(n=26)\end{array}$ & $\begin{array}{l}\text { Group II } \\
(\mathbf{n}=\mathbf{1 5})\end{array}$ & $\begin{array}{c}P \\
\text { value }\end{array}$ \\
\hline \multicolumn{4}{|l|}{ Preoperative characteristics } \\
\hline Age $(y$, mean $\pm \mathrm{SD})$ & $67.3 \pm 10.0$ & $69.7 \pm 11.5$ & .50 \\
\hline Female (no.) & $15(58 \%)$ & $67(10 \%)$ & .58 \\
\hline Hypertension (no.) & $23(88 \%)$ & $13(87 \%)$ & .87 \\
\hline $\begin{array}{c}\text { Coronary artery } \\
\text { disease (no.) }\end{array}$ & $2(8 \%)$ & $1(7 \%)$ & .70 \\
\hline Previous stroke (no.) & $1(4 \%)$ & $1(7 \%)$ & .70 \\
\hline Marfan syndrome (no.) & $1(4 \%)$ & $1(7 \%)$ & .70 \\
\hline $\begin{array}{l}\text { Baseline NIHSS score } \\
\quad(\text { mean } \pm \mathrm{SD})\end{array}$ & $7.0 \pm 5.6$ & $17.3 \pm 7.2$ & $<.00$ \\
\hline $\begin{array}{l}\text { Time to surgery } \\
\qquad(\mathrm{h}, \text { mean } \pm \mathrm{SD})\end{array}$ & $6.5 \pm 3.3$ & $48.1 \pm 59.0$ & .02 \\
\hline $\begin{array}{l}\text { Occlusion of carotid artery } \\
\text { (no.) }\end{array}$ & $7(27 \%)$ & $8(53 \%)$ & .09 \\
\hline \multicolumn{4}{|l|}{ Intraoperative variables } \\
\hline $\begin{array}{l}\text { Cardiopulmonary bypass time } \\
\quad(\text { min, mean } \pm \mathrm{SD})\end{array}$ & $196.3 \pm 76.8$ & $191.3 \pm 67.7$ & .84 \\
\hline $\begin{array}{l}\text { Crossclamp time } \\
\quad(\text { min, mean } \pm \mathrm{SD})\end{array}$ & $119.2 \pm 51.4$ & $123.0 \pm 62.0$ & .84 \\
\hline $\begin{array}{l}\text { Lowest core temperature } \\
\qquad\left({ }^{\circ} \mathrm{C}, \text { mean } \pm \mathrm{SD}\right)\end{array}$ & $23.0 \pm 2.3$ & $22.0 \pm 3.8$ & .35 \\
\hline $\begin{array}{l}\text { Axillary arterial perfusion } \\
\text { (no.) }\end{array}$ & $6(23 \%)$ & $6(40 \%)$ & .26 \\
\hline $\begin{array}{l}\text { Selective cerebral perfusion } \\
\quad \text { (no.) }\end{array}$ & $12(46 \%)$ & $7(47 \%)$ & .46 \\
\hline $\begin{array}{l}\text { Retrograde cerebral perfusion } \\
\quad \text { (no.) }\end{array}$ & $14(54 \%)$ & $8(53 \%)$ & .46 \\
\hline Hemiarch replacement (no.) & $7(27 \%)$ & $8(53 \%)$ & .10 \\
\hline Total arch replacement (no.) & $19(73 \%)$ & $7(47 \%)$ & .10 \\
\hline
\end{tabular}

Group I, Neurologic improvement; Group II, lack of neurologic improvement; NIHSS, National Institutes of Health Stroke Scale.

univariate analysis (Table 1). In the logistic regression analysis, the baseline NIHSS score (odds ratio, $6.7 ; 95 \%$ confidence interval, $1.4-32.4 ; P=.02$ ) and time to surgery (odds ratio, $14.6 ; 95 \%$ confidence interval, $2.7-8.5 ; P=.002$ ) were associated with the lack of neurologic improvement.

TABLE 2. Postoperative outcomes

\begin{tabular}{lccc}
\hline & $\begin{array}{c}\text { Group I } \\
(\mathbf{n = 2 6})\end{array}$ & $\begin{array}{c}\text { Group II } \\
(\mathbf{n}=\mathbf{1 5})\end{array}$ & $\begin{array}{c}\boldsymbol{P} \\
\text { value }\end{array}$ \\
\hline 30-day mortality (no.) & 0 & $6(40 \%)$ & .009 \\
Intensive care unit stay (d, & $4.8 \pm 3.3$ & $5.7 \pm 3.5$ & .53 \\
$\quad$ mean \pm SD) & & & \\
Hospital stay (d, mean \pm SD) & $21.2 \pm 20.8$ & $33.3 \pm 28.2$ & .11 \\
Brain infarction (no.) & $11(42 \%)$ & $12(80 \%)$ & .01 \\
$\begin{array}{l}\text { Occlusion of carotid artery } \\
\quad(\text { no.) }\end{array}$ & 0 & $3(20 \%)$ & .08 \\
$\begin{array}{l}\text { Postoperative NIHSS score } \\
\quad(\text { mean } \pm \text { SD) }\end{array}$ & $2.0 \pm 3.1$ & $22.7 \pm 14.7$ & $<.001$ \\
\hline
\end{tabular}

Group I, Neurologic improvement; Group II, lack of neurologic improvement; NIHSS, National Institutes of Health Stroke Scale.
Neither brain protection method nor extent of aortic repair was related to lack of improvement.

The areas under the receiver operating characteristics curves for the baseline NIHSS score and the time to surgery were $0.90 \pm 0.05$ and $0.77 \pm 0.09$, respectively (Figure 1). The optimal cutoff value of baseline NIHSS score for predicting lack of neurologic improvement was 11 (sensitivity $80 \%$, specificity $85 \%$ ), and that of time to surgery was 9.1 hours (sensitivity $67 \%$, specificity $96 \%$ ).

Figure 2 shows the changes between baseline and postoperative NIHSS scores. Neurologic recovery rates were $88 \%$ among patients with a baseline NIHSS score not greater than $11(\mathrm{n}=24)$ and $85 \%$ among those with a time to surgery not exceeding 9.1 hours $(n=20)$. Three of the 20 patients with a time to surgery not longer than 9.1 hours showed neurologic worsening. Postoperative carotid ultrasonography showed the persistent occlusion of carotid artery despite aortic repair. According to subgroup analyses combining the 2 cited risk factors (time to surgery $>9.1$ hours and baseline NIHSS score $>11$ ), lack of neurologic recovery was noted in $0 \%$ of patients with no risk factors $(\mathrm{n}=15)$, in $25 \%$ of patients with 1 risk factor $(\mathrm{n}=16)$, and in $100 \%$ of patients with both risk factors $(n=10)$. The positive likelihood ratio of neurologic recovery was 3.8 when at least 1 of these risk factors was present.

\section{Lack of Neurologic Improvement as a Predictor of Long-Term Survival}

Overall 30 -day mortality was $14.6 \%, 0 \%$ in group I and $40 \%$ in group II $(p=.009)$. Large hemispheric cerebral infarction with edema accounted for all deaths within 30 days. According to subgroup analyses combining 2 risk factors (time to surgery $>9.1$ hours and baseline NIHSS score $>11$ ), 30-day mortalities among patients with 0,1 , and 2 risk factors were $0 \%, 13 \%$, and $50 \%$, respectively. Follow-up information was available for all discharged patients, and follow-up was comparable in duration between the groups. After a mean follow-up of 4.8 years (range, $0.1-11.4$ years), late mortality was 9 patients. Three patients had large infarctions, required prolonged hospital stays and transfer to an outside hospital, and eventually died of sepsis within 1 year after surgery. Other modes of death were pneumonia in 3 cases, cerebral hemorrhage in 1 , heart failure in 1 , and sudden cardiac death in 1.

Overall survivals were $65 \% \pm 8 \%$ at 5 years and $59 \% \pm$ $9 \%$ at 10 years. The survivals after 5 years of follow-up were $84 \% \pm 7 \%$ in group I and $33 \% \pm 12 \%$ in group II $(P<.001$ by log-rank test; Figure 3$)$. The lack of neurologic improvement was significantly associated with poor longterm survival.

\section{DISCUSSION}

This is a descriptive report of a single-center experience with cardiac surgery in 41 patients with acute aortic 


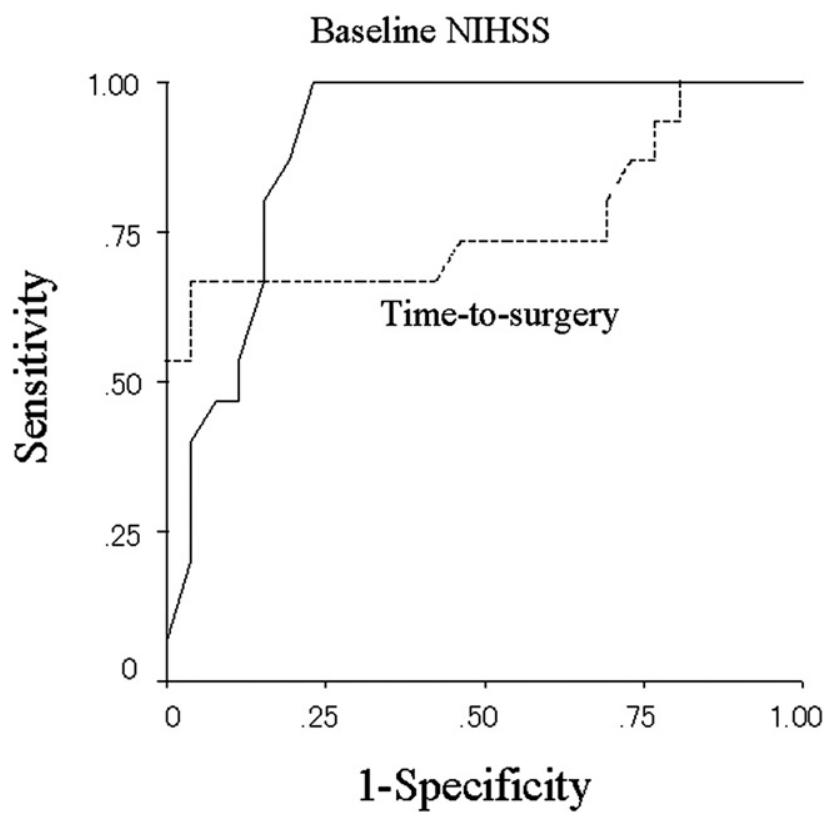

FIGURE 1. The areas under the receiver operating characteristics curve in baseline National Institutes of Health Stroke Scale (NIHSS) score and time to surgery.

dissection and cerebral malperfusion. In this series, we found that baseline NIHSS score greater than 11 and a time to surgery longer than 9.1 hours were associated with lack of neurologic recovery after aortic repair.

The ideal therapeutic approach to patients with cerebral malperfusion has not been established. Since the classic report by Fann and associates, ${ }^{10}$ preoperative neurologic deficits resulting from cerebral malperfusion have been reported as a sign of poor prognosis. Estrera and associates ${ }^{2}$

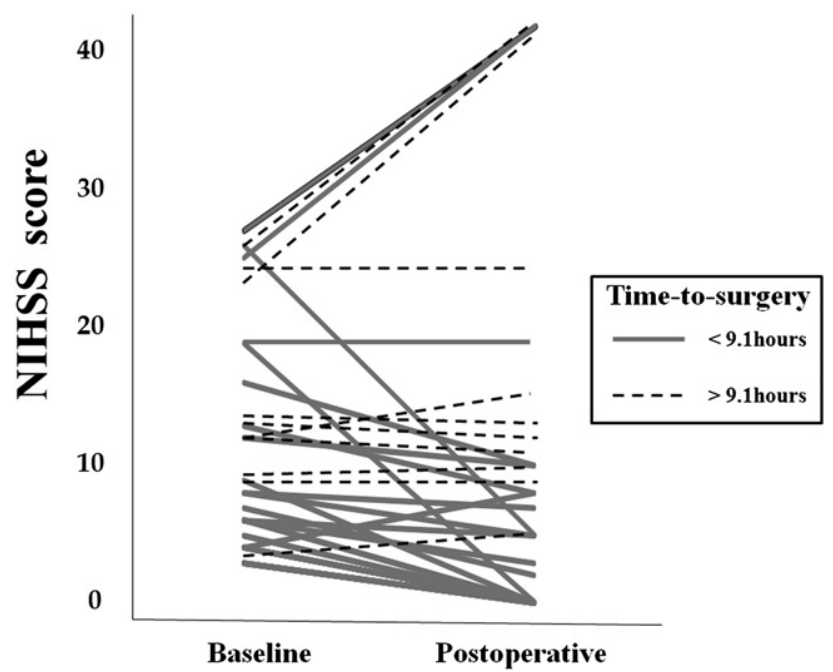

FIGURE 2. Changes between baseline and postoperative National Institutes of Health Stroke Scale (NIHSS) score. Solid and broken lines shows patients with a time to surgery not longer than 9 hours and those with a time to surgery longer than 9 hours, respectively.

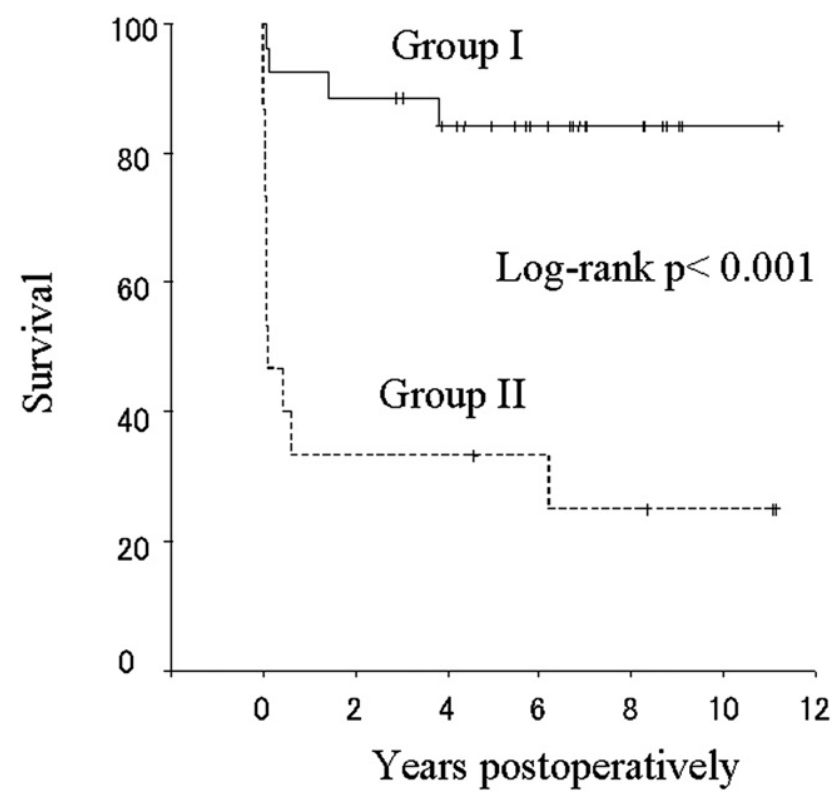

FIGURE 3. Long-term survival comparison between group I (neurologic improvement) and group II (lack of neurologic improvement).

reported a favorable outcome (improved mortality $18.8 \%$ ) in a case series of 16 patients with aortic dissection and stroke, with the best results found among the patients who underwent surgical repair within 10 hours after the onset of cerebral symptoms. Our results were comparable, with a $14.8 \%$ 30-day mortality and 39\% complete resolution of cerebral symptoms after immediate surgical repair. We also found that immediate surgical repair within 9.1 hours from the onset of symptoms was associated with good neurologic recovery. Thirty patients $(73 \%)$ underwent immediate surgery within 9.1 hours in our series, and 25 of them had postoperative improvement in neurologic status. Also in Estrera and associates' series, ${ }^{2}$ neurologic function was regained by 7 of 10 patients who underwent immediate surgical repair, defined as within 10 hours. We also, however, observed postoperative deterioration and eventual cerebral death of 3 patients who had persistent occlusion of the carotid artery despite central aortic repair. We therefore agree with the suggestion of Estrera and associates ${ }^{2}$ that the time to surgery may influence neurologic recovery in patients with cerebral malperfusion, although we now believe that the most important predictor of neurologic recovery is not actually the time to surgery but rather the time to relief of cerebral malperfusion. Recently, we developed a controlled earlier reperfusion system that would allow us to reperfuse the ischemic brain in the emergency department soon after the diagnosis of cerebral malperfusion.

Intentional delay of aortic repair until after recovery of neurologic condition is among the therapeutic options for acute aortic dissection with cerebral malperfusion and minimizes the effects of cardiopulmonary bypass and 
reperfusion injury. ${ }^{11-13}$ This approach may enable aortic repair without brain edema formation or hemorrhagic transformation. Piotrowski and associates ${ }^{14}$ showed that carotid endarterectomy after acute stroke can be performed with no increase in morbidity or mortality as long as neurologic recovery has reached a plateau. In patients with acute type A dissection, however, the delay might result in subsequent death as a result of rupture, cardiac tamponade, or recurrent dissection. In previous studies advocating intentional delay, $15 \%$ to $25 \%$ of patients died of aortic rupture or low output syndrome during the waiting period, ranging from 5 days to 81 days from the onset of symptoms. ${ }^{11-13}$ An intentionally delayed approach thus cannot guarantee favorable results.

We also found lower preoperative NIHSS score to be strongly associated with good neurologic recovery. A correlation between NIHSS score and the likelihood of large stroke from a carotid or proximal cerebral arterial occlusion has been described in several published reports. ${ }^{15-18} \mathrm{~A}$ cutoff NIHSS score greater than 10 yields a high sensitivity (more than 90\%) for finding a carotid or proximal cerebral arterial occlusion and has usually been used to triage patients to further intervention in landmark stroke trials. ${ }^{19}$ The negative predictive value of the NIHSS score, however, has been poor. NIHSS scores not more than 10 has been observed in half of patients with carotid or proximal arterial occlusion. ${ }^{20}$ In this study, patients with a baseline NIHSS score not more than 10 accounted for $59 \%$ of the studied population. Recent reports ${ }^{20}$ have noted that patients with a large stroke volume and a low NIHSS score are more likely to have a large penumbra of at-risk tissue and that the patient with both a large stroke volume and a low NIHSS score is considered be an ideal candidate for aggressive revascularization.

The optimal brain protection method during aortic arch surgery for patients with cerebral malperfusion still remains unclear. Estrera and associates ${ }^{2}$ reported $19 \%$ operative mortality and $50 \%$ neurologic recovery rate among 16 patients with aortic dissection and cerebral malperfusion who underwent aortic repair with profound hypothermic arrest and retrograde cerebral perfusion. Pocar and associates ${ }^{21}$ reported $0 \%$ mortality and $80 \%$ neurologic recovery rate for patients in a coma who were operated on with selective cerebral perfusion. With respect to resolving cerebral malperfusion as early as possible, selective cerebral perfusion has significant advantage relative to retrograde cerebral perfusion. Recently we developed controlled earlier reperfusion system to be used in the emergency department.

In summary, NIHSS scores greater than 11 and times to surgery longer than 9.1 hours were both predictors of lack of neurologic improvement after aortic repair. Our study suggests that patients with NIHSS scores of 11 or less can be treated with immediate aortic repair within 9.1 hours from neurologic symptom onset.

\section{References}

1. Girdaukas E, Kuntze T, Birger MA, Falk V, Mohr FW. Surgical risk of preoperative malperfusion in acute type A dissection. J Thorac Cardiovasc Surg. 2009;138:1363-9.

2. Estrera AL, Garami Z, Miller CC, Porat EE, Achouh PE, Dhareshwar J, et al. Acute type A aortic dissection complicated by stroke: can immediate repair be performed safely? J Thorac Cardiovasc Surg. 2006;132:1404-8.

3. Molina CA, Montaner J, Arenillas JF, Ribo M, Rubiera M, Alvarez-Sabín J. Differential pattern of tissue plasminogen activator-induced proximal middle cerebral artery recanalization among stroke subtypes. Stroke. 2004;35:486-90.

4. Munakata H, Okada K, Kano H, Hino Y, Matsumori M, Okita Y. Controlled earlier reperfusion for brain ischemia caused by acute aortic dissection. Ann Thorac Surg. 2009;87:e27-8.

5. Crawford ES, Kirklin JW, Naftel DC, Svensson LG, Coselli JS, Safi HJ. Surgery for acute dissection of ascending aorta. Should the arch be included? J Thorac Cardiovasc Surg. 1992;104:46-59.

6. Brott T, Adams HP Jr, Olinger CP, Marler JR, Barsan WG, Biller J, et al. Measurements of acute cerebral infarction: a clinical examination scale. Stroke. 1989; 20:864-70.

7. Generalized efficacy of t-PA for acute stroke: subgroup analysis of the NINDS t-PA stroke trial. Stroke. 1997;28:2119-25.

8. Wityk RJ, Pessin MS, Kaplan RF, Caplan LR. Serial assessment of acute stroke of acute stroke using the NIH stroke scale. Stroke. 1994;25:362-5. Erratum in: Stroke. 1994;25:1300.

9. Brott T, Marler JR, Olinger CP, Adams HP Jr, Tomsick T, Barsan WG, et al. Measurements of acute cerebral infarction: lesion size by computed tomography. Stroke. 1989;20:871-5.

10. Fann JI, Sarris GE, Miller DC, Mitchell RS, Oyer PE, Stinson EB, et al. Surgical management of acute aortic dissection complicated by stroke. Circulation. 1989; 80:I257-63.

11. Piccione W Jr, Hamilton IN, Najafi H. Intentional delayed repair of acute dissection of the ascending aorta complicated by stroke. J Thorac Cardiovasc Surg. 1995;109:807-8.

12. Eren A, Gulbins H, Pritisanac A, Hannekum A. Delayed repair of Stanford typeA dissection following fulminant cerebral infarction. Thorac Cardiovasc Surg. 2005;53:321-2.

13. Fukuda I, Imazuru T. Intentional delay of surgery for acute type A dissection with stroke. J Thorac Cardiovasc Surg. 2003;126:290-1.

14. Piotrowski JJ, Bernhard VM, Rubin JR, McIntyre KE, Malone JM, Parent FN 3rd, et al. Timing of carotid endarterectomy after acute stroke. $J$ Vasc Surg. 1990;11:45-52.

15. Derex L, Nighoghossian N, Hermier M, Adeleine P, Froment JC, Trouillas P. Early detection of cerebral arterial occlusion on magnetic resonance angiography: predictive value of the baseline NIHSS score and impact on neurological outcome. Cerebrovasc Dis. 2002;13:225-9.

16. Lewandowski CA, Frankel M, Tomsick TA, Broderick J, Frey J, Clark W, et al. Combined intravenous and intra-arterial r-TPA versus intra-arterial therapy of acute ischemic stroke: Emergency Management of Stroke (EMS) Bridging Trial. Stroke. 1999;30:2598-605.

17. Nakajima M, Kimura K, Ogata T, Tanaka T, Uchino M, Minematsu K. Relationships between angiographic findings and National Institute of Health Stroke Scale score in cases of hyperacute carotid ischemic stroke. AJNR Am J Neuroradiol. 2004;25:238-41.

18. Fischer U, Arnold M, Nedeltchev K, Brekenfeld C, Ballinari P, Remonda L, et al. NIHSS score and arteriographic findings in acute ischemic stroke. Stroke. 2005; $36: 2121-5$.

19. Clinical Trials.gov registry [Internet]. Interventional Management of Stroke (IMS) III Trial (IMSIII) [cited 2009 Feb 16], Available from:. Bethesda (MD): National Library of Medicine (US); 1993 http://www.clinicaltrials.gov/ct2/ show/NCT00359424.

20. Maas MB, Furie KL, Lev MH, Ay H, Singhal AB, Greer DM, et al. National Institutes of Health Stroke Scale score is poorly predictive of proximal occlusion in acute cerebral ischemia. Stroke. 2009;40:2988-93.

21. Pocar M, Passolunghi D, Moneta A, Mattioli R, Donatelli F. Coma might not preclude emergency operation in acute aortic dissection. Ann Thorac Surg. 2006;81: 1348-51. 